\title{
Geochemical perspectives from a new aerosol chemical mass closure
}

\author{
B. Guinot, H. Cachier, and K. Oikonomou \\ Laboratoire des Sciences du Climat et de l'Environnement, Gif-sur-Yvette, France \\ Received: 14 September 2006 - Published in Atmos. Chem. Phys. Discuss.: 27 November 2006 \\ Revised: 1 March 2007 - Accepted: 19 March 2007 - Published: 27 March 2007
}

\begin{abstract}
The aerosol chemical mass closure is revisited and a simple and inexpensive methodology is proposed. This methodology relies on data obtained for aerosol mass, and concentration of the major ions and the two main carbon components, the organic carbon (OC) and the black carbon (BC). Atmospheric particles are separated into coarse $(\mathrm{AD}>2 \mu \mathrm{m})$ and fine $(\mathrm{AD}<2 \mu \mathrm{m})$ fractions and are treated separately. For the coarse fraction the carbonaceous component is minor and assumption is made for the conversion factor $\boldsymbol{k}$ of OC-to-POM (Particulate Organic Matter) which is fixed to the value of 1.8 accounting for secondary species. The coarse soluble calcium is shown to display a correlation (regression coefficient $\boldsymbol{f}$, y axis intercept $\boldsymbol{b}$ ) with the missing mass. Conversely, the fine fraction is dominated by organic species and assumption is made for dust which is assumed to have the same $f$ factor as the coarse mode dust. The fine mode mass obtained from chemical analyses is then adjusted to the actual weighed mass by tuning the $\boldsymbol{k}$ conversion factor. The $\boldsymbol{k}$ coefficient is kept different in the two modes due to the expected different origins of the organic particles. Using the $f$ and $\mathrm{k}$ coefficient obtained from the data set, the mass closure is reached for each individual sample with an undetermined fraction less than $10 \%$. The procedure has been applied to different urban and peri-urban environments in Europe and in Beijing and its efficiency and uncertainties on $\boldsymbol{f}$ and $\boldsymbol{k}$ values are discussed. The $\boldsymbol{f}$ and $\boldsymbol{k}$ coefficients are shown to offer consistent geochemical indications on aerosol origin and transformations. $f$ allows to retrieve dust mass and its value accounting for $\mathrm{Ca}$ abundance in dust at the site of investigation may serve as an indicator of dust origin and aerosol interactions with anthropogenic acids. $f$ values were found to vary in the $0.08-0.12$ range in European urban areas, and a broader range in Beijing (0.01-0.16). As expected, $\boldsymbol{k}$ appears to be a relevant proxy for particle origin and ageing and
\end{abstract}

Correspondence to: $\mathrm{H}$. Cachier

(cachier@1sce.cnrs-gif.fr) varies in the 1.4-1.8 range. For Beijing, $\boldsymbol{k}$ exhibits high values of about 1.7 in winter and summer. Winter values suggest that fresh coal aerosol might be responsible for such a high $\boldsymbol{k}$ value, which was not taken into account in previous works.

\section{Introduction}

Aerosols are found in different size-classes which account for their various environmental effects, such as respiratory diseases, visibility impairment, and radiative forcing (Donaldson et al., 2001; Zhang et al., 2003; Penner et al., 2004). They also contribute to numerous atmospheric processes, and may also serve as nuclei on which clouds form (Kaufman et al., 2002). Of interest too are nucleation and heterogeneous chemical reaction sequences producing condensable particulate products from precursor gases such as sulphur dioxide, nitrogen oxides and organic vapours. Particles thus formed are defined as secondary aerosols, and are present in the whole size spectrum both for number and mass distributions (Seinfeld and Pandis, 1998).

One of the major challenges in aerosol science is to account for aerosol sources and transformation processes at local, regional and global scales in order to better understand their effects on the environment, and subsequently support relevant environmental protection policies. This challenge calls for a broad field of investigations, from the relatively simple situations encountered in developed countries to the intense multi-sources pattern observed in developing cities. Mass closure attempts represent a unique tool to accept the challenge.

For this purpose, experimental campaigns generally consist in allocated samplings on different filter types, running simultaneously at a representative site. Such experiments allow an extensive aerosol characterisation at different possible timescales, from diurnal to inter-annual. Particle size segregation is a critical parameter to identify the most important

Published by Copernicus GmbH on behalf of the European Geosciences Union. 
contributors to the aerosol fine and coarse masses and to assess their origin and behaviour - primary or secondary, natural or anthropogenic, and state of mixing (Ten Brick et al., 2004; Berner et al., 2004).

An aerosol mass closure is achieved when the gravimetric measurement of filter samples matches the sum of the masses of the individually identified chemical species (the reconstructed mass). Any attempt, however, includes hypotheses to estimate dust material and organic matter, which possibly largely contribute to the aerosol mass. Previous works present a diversity of approaches to constrain the uncertainties associated to these hypotheses (Andrews et al., 2000; Putaud et al., 2004a; Rees et al., 2004). But no general pathway clearly emerges.

Here, we attempt to define a simple and inexpensive filterbased protocol which may apply to urban and peri-urban sites of various complexities. This methodology provides $\mathrm{Ca}^{2+} /$ dust $(\boldsymbol{f})$ and OC/POM $(\boldsymbol{k})$ conversion factors and has been validated on approximately 500 samplings from 11 field campaigns conducted in different environments in Europe and in Beijing, China. This paper details the methodology and furthermore shows that estimated coefficients $(f)$ and $(\boldsymbol{k})$ may provide an interesting insight on particle origin and transformations.

\section{Experimental}

\subsection{Sampling protocol}

All field experiments have used the following protocol. Considering a complex multi-source aerosol phase, a distinction between fine and coarse particles is relevant since they are remarkably distinct in origin and nature. Each mode is indeed closely related to a type of source, or to characteristic physical and chemical generation processes. Coarse particles (larger than $1000 \mathrm{~nm}$ ) are usually primary particles mechanically generated from wind erosion of dust material or sea surface. Interestingly, these particles provide a surface of basic material on which volatile species, and especially acidic ones, may attach. Primary particles from combustion, like fly ash, may also be found on this coarse mode. Fine particles comprise the nucleation (less than $20 \mathrm{~nm}$ ), the Aitken (ranging from 20 to $90 \mathrm{~nm}$ ) and the accumulation mode $(90 \mathrm{~nm}<\mathrm{AED}<1000 \mathrm{~nm})$. They are generated from both primary sources (combustion) and secondary processes (conversion of gaseous precursors) (Whitby, 1978; Hoppel and Frick, 1990; Covert et al., 1992).

In our work, distinction between coarse and fine particles is operationally defined using stack filter units (SFU) samplers working at $1 \mathrm{~m}^{3} \mathrm{~h}^{-1}$ with two filters of different pore size used as follows: Nuclepore $8.0 \mu \mathrm{m}$ filters collect particles with aerodynamic diameters higher than $2 \mu \mathrm{m}$, while downstream $0.4 \mu \mathrm{m}$ filters collect particles smaller than $2 \mu \mathrm{m}$ (John et al., 1983). In order to maintain the cut- off and the analysis reliability, sampling duration is adapted to obtain aerosol loadings $<500 \mu \mathrm{g} /$ filter. Aerosols are weighed from these SFU samples prior to dissolution for Ion Chromatography (IC). Bulk measurements of carbonaceous aerosols are performed using Whatman QM-A quartz-fibre filters. Insoluble species (other than BC) are assessed as dust material.

Chemical size distributions are achieved using DEKATI 13-stage cascade impactors, mounted with either quartz-fibre or Zefluor filters for the analysis of carbonaceous matter and soluble species, respectively.

\subsection{Gravimetric measurements}

All Nuclepore filters are weighed before and after sampling, using a Mettler Microbalance UMT3 with $1 \mu \mathrm{g}$ sensitivity. Filter weighing is achieved after 24-h equilibration at room temperature with atmospheric relative humidity $(\mathrm{RH})$ maintained below $30 \%$. For this $\mathrm{RH}$, the ion water content has been shown to be less than $10 \%$ and may be considered as negligible (Sciare et al., 2005 and references herein). RH is set to refer to a dry aerosol in order to minimize uncertainties due to water adsorption-desorption by the filter media and aerosol particles (MacMurry, 2000). Typical uncertainty for our gravimetric measurements $(\Delta \mathrm{m})$ is of the order of $\pm 5 \mu \mathrm{g}$, which represents 1 to $2 \%$ of the total aerosol mass in all the datasets involved in this work.

Zefluor filters used for cascade impactors are weighed using the same protocol. Averaged uncertainty on the mass value presents significant differences between the stages, from $\Delta \mathrm{m}=3-5 \%$ for the 10 first stages $(>150 \mathrm{~nm})$, whereas the uncertainty is up to $20 \%$ for the 3 other stages $(<150 \mathrm{~nm})$.

\subsection{Inorganic soluble species}

After weighing, Nuclepore filters are analysed by IC for the determination of the major anions and cations using the following protocol. Filter samples are extracted in $15 \mathrm{ml}$ of Milli-Q water for $45 \mathrm{~min}$ in a sonic bath. Fifty microlitres of chloroform are then added to each sample to prevent bacteria activity. Samples are filtered just before the analysis using Acrodisc filters (Pall Gelmann) with a porosity of $0.4 \mu \mathrm{m}$. Analysis of cations $\left(\mathrm{Na}^{+}, \mathrm{NH}_{4}^{+}, \mathrm{K}^{+}, \mathrm{Mg}^{2+}, \mathrm{Ca}^{2+}\right)$ takes place on a 4-mm CS12 column and Dionex IC (Model DX600 ) equipped with a reagent free system (automated eluent generation and self-regenerating suppression). Analysis of the major inorganic anions $\left(\mathrm{Cl}^{-}, \mathrm{NO}_{3}^{-}, \mathrm{SO}_{4}^{2-}\right)$ takes place on an 4-mm diameter AS11 column and Dionex IC (Model DX-600) also equipped with a reagent free system. Blank filters were systematically taken in the field without showing any significant contamination during sampling, handling or shipment.

In our mass closure attempts it must be noted that organic acids (which are identified on chromatograms and provide useful indication about sources, transformation processes 
Table 1. Carbon analysis: correlation between the 2-step thermal method and thermal optical method data (slope and correlation coefficients $\left.\left(r^{2}\right)\right)$.

\begin{tabular}{llll}
\hline & $\begin{array}{l}\text { Beijing Intercomp C } \\
n=14\end{array}$ & $\begin{array}{l}\text { Beijing Pek1 } \\
n=35\end{array}$ & $\begin{array}{l}\text { Florence } \\
n=42\end{array}$ \\
\hline TC Thermal/DRI $_{a}$ & $1.005(0.99)$ & - & $0.988(0.98)$ \\
BC Thermal/DRI $a$ & $0.975(0.82)$ & $0.846(0.81)$ & $0.742(0.61)$ \\
BC Thermal/NIOSH & $1.196(0.91)$ & - & $1.233(0.63)$ \\
OC Thermal/DRI & $1.079(0.99)$ & $1.233(0.89)$ & $1.089(0.95)$ \\
OC Thermal/NIOSH & $0.971(0.99)$ & - & $1.039(0.94)$ \\
\hline
\end{tabular}

$n$ accounts for the number of samples

and state of mixing) are not included in the fraction hereafter termed ions, as they are already included in estimates of the particulate organic matter.

Averaged uncertainty on the major ions results is of the order of $10 \mathrm{ppb}$, which represents less than $2 \%$ of uncertainty in atmospheric ion concentrations for most of our field campaigns.

\subsection{Carbonaceous fraction}

The total carbon fraction (TC) includes black carbon (BC) and organic carbon (OC). In our 2-step procedure (Cachier et al., 1989), carbonate $\left(\mathrm{CO}_{3}^{2-}\right)$ is systematically evolved prior to analysis to avoid any interference with the other $\mathrm{BC}$ or OC components. This point is particularly important at sites highly impacted by dust aerosols (e.g. in Beijing).

Carbon determination encounters two major difficulties, one related to sampling, the other to analysis. By itself, carbon particles sampling may create two contradictory artefacts. The positive artefact enhances the carbon content by the capture of volatile organic carbon (VOC) which is favoured by the fibrous matrix of the quartz filter. To minimize the artefact which is assumed to be enhanced by filter surface activation, our cleaning procedure consists in pre-firing during $48 \mathrm{~h}$ the quartz filter at relatively lower temperature $\left(400^{\circ} \mathrm{C}\right)$ than what is generally performed $\left(600\right.$ to $\left.900^{\circ} \mathrm{C}\right)$, still leading to satisfactory blank values of $0.8 \pm 0.05 \mu \mathrm{gTC} \mathrm{cm}^{-2}$ and $0.20 \pm 0.10 \mu \mathrm{gBC} \mathrm{cm}^{-2}$. On the other hand, the negative artefact lowers the carbon content by stripping the particle coating of the semi-volatile organic matter (SVOM). We eventually get rid of both positive artefacts by heating samples at $60^{\circ} \mathrm{C}$ for $15 \mathrm{~min}$ prior to analysis, as similarly reported by Malm et al. (2005).

The analytical determination of BC and OC is still open to discussion (Ten Brink et al., 2004). Regarding the split between $\mathrm{BC}$ and $\mathrm{OC}$, the main problems encountered in the analysis are related to two contradictory artefacts: the charring of $\mathrm{OC}$, or the incomplete removal of organic compounds, which may lead to an overestimate of BC; and conversely the untimely departure of $\mathrm{BC}$. To assess the quality of our 2-step approach for the BC-OC split, we compared our reference method to two thermal protocols both implemented in the Sunset Inc. OCEC instrument working in transmission for the laser beam. The first of these two protocols uses the temperature programme from the Desert Research Institute method (DRI) developed by (Chow et al., 1993), and is hereafter referred to as $\mathrm{DRI}_{a}$. The second one is the NIOSH method (Birch and Cary, 1996), which currently serves to determine BC and OC in the NIOSH 5040 protocol.

These three methods were applied to two sets of filters, collected ( $i$ ) $5 \mathrm{~km}$ North from Beijing downtown, at the top of the National Research Centre for Environmental Analysis \& Measurements, in January 2003 (Results refer to "Beijing IntercompC" campaign in Table 1), and (ii) at Florence, July 2002-June 2003. An additional comparison of our reference method with the $\mathrm{DRI}_{a}$ method was performed during Pek1, in January 2003 in Beijing downtown. All samples were previously treated to remove carbonate. Intercomparison data are presented in Table 1. TC results are found similar and highly correlated whatever the analytical method used $\left(\mathrm{r}^{2}\right.$ higher than 0.99) whereas BC and OC results show higher discrepancy. In previous intercomparison exercises (Schmid et al., 2001; Ten Brink et al., 2004), our laboratory simple method was found to provide results situated in the middle of the range of values. It is also the case for the intercomparisons conducted in this work. OC uncertainty from our reference method to the others ranges within $20-25 \%$. Because of the large abundance of OC especially in the fine fraction of urban aerosols, the analytical split between $\mathrm{BC}$ and OC may bring non-negligible bias in the chemical mass closure which relies on the OC-to-POM (Particulate Organic Matter) conversion achieved using an adequate coefficient $\boldsymbol{k}$ (see Sect. 4.3). A 20\% OC uncertainty may influence a typical $\mathrm{PM}_{2.5}$ chemical mass by $10 \%$, which implies up to $20 \%$ variability in $\boldsymbol{k}$ values.

\subsection{Dust material}

Multi-element techniques such as XRF, INAA and PIXE are commonly used for analysing mineral dust, but they still need assumptions regarding the unaccounted presence of heteroatoms (Andrews et al., 2000). Dust material is made 

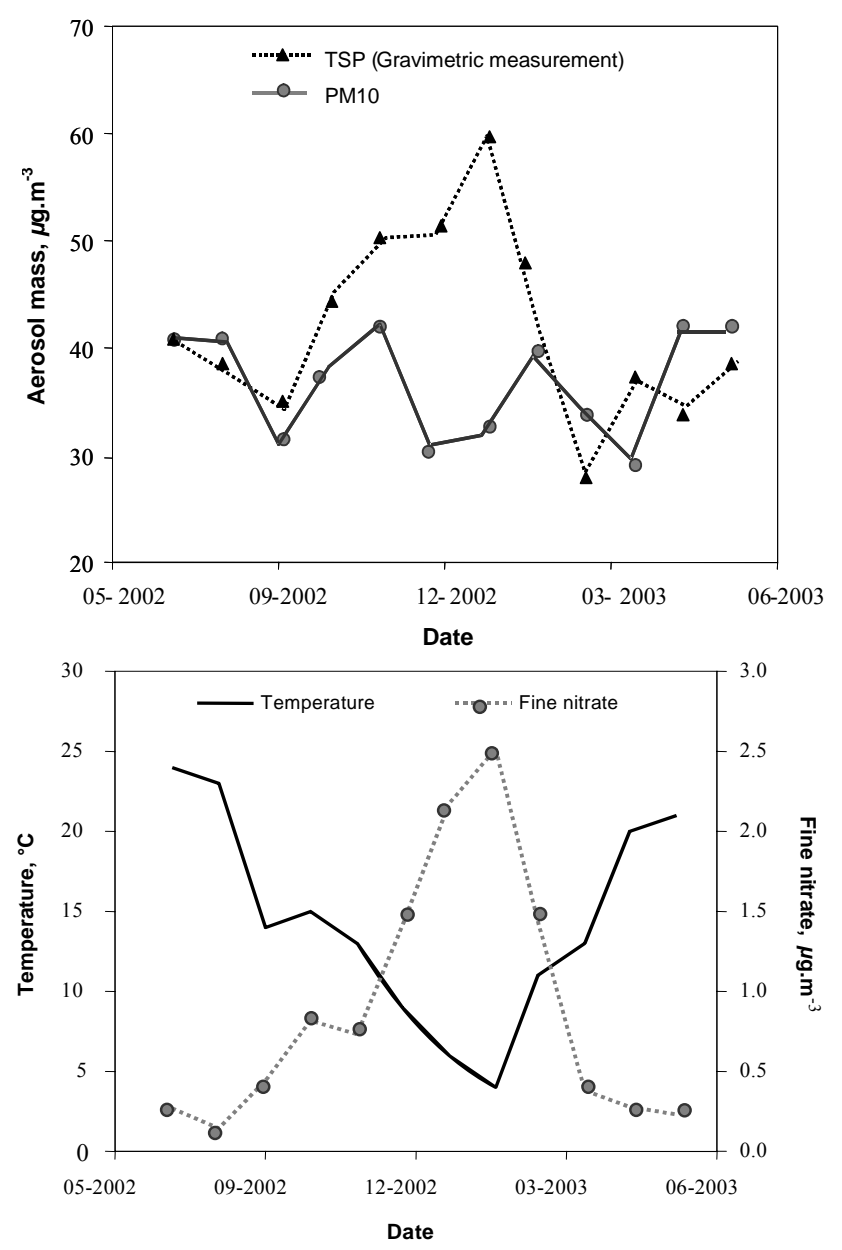

Fig. 1. Monthly averages at Florence (July 2002-June 2003). (a) PM-10 obtained with TEOM and TPM by filter gravimetric measurements. (b) TPM nitrate concentrations as a function of ambient temperature.

of elements, in various relative amounts, depending on the source location but many works rely on the "Bowen ratios" characterizing a mean desert composition to account for dust composition (Bowen, 1966). In regions where desert dust mix with local resuspension, this may not fully picture the actual dust composition.

Calcium is a major component of dust, along with $\mathrm{Si}, \mathrm{Al}$ and $\mathrm{Fe}$, where it is mainly found as calcium carbonate. It has been recently suggested that $\mathrm{Ca}^{2+}$ could be used to estimate the concentration of dust matter in the atmosphere. Putaud et al. (2004a) estimated the dust component at Monte Cimone in Italy during two identified dust episodes. They found a fair regression between $\mathrm{Ca}^{2+}$ from IC and mineral dust from weighing. They also reported two different typical abundances of $\mathrm{Ca}^{2+}$ in dust material depending on dust origin: $5.6 \%$ for non-Saharan dust periods, and $15 \%$ for Saharan dust periods. Using a slightly different approach, during the
MINOS campaign in Crete Island, Sciare et al. (2005) compared $n s s-\mathrm{Ca}^{2+}\left(n s s-\mathrm{Ca}^{2+}=\mathrm{Ca}^{2+}-\left(0.038 \times \mathrm{Na}^{+}\right)\right.$obtained directly from IC and indirectly from aluminium and iron concentrations obtained by PIXE, using typical elemental ratios. A proportion of $10.96 \pm 1.0 \%$ of $n s s-\mathrm{Ca}^{2+}$ in dust was found. Both above-cited works therefore suggest that the $\mathrm{Ca}^{2+}$ to dust ratio could serve as an indicator of dust origin. In this purpose, one key feature of our experimental protocol is the systematic and total dissolution of calcium during the aerosol extraction stage, which can thus be analysed by IC as soluble calcium: this has been previously verified by comparison of soluble $\mathrm{Ca}^{2+}$ data and total Ca obtained by PIXE (Sciare et al., 2005). We therefore attempt to use soluble calcium analysed by IC to obtain an indirect and simple estimate of dust mass concentration. In the calculations, for simplification, we do not distinguish soluble calcium $\left(\mathrm{Ca}^{2+}\right)$ from non seasalt calcium $n s s-\mathrm{Ca}^{2+}$ in any of our experiments. It may be noted that in our work dust material always refers to insoluble species including $\mathrm{CaCO}_{3}$, and excluding the carbonaceous $\mathrm{BC}$ fraction. The soluble fraction termed ions comprises neither calcium nor carbonate.

\section{Field campaigns: site description and dataset presen- tation}

In the frame of various projects, the aerosol chemical composition was investigated from analysis of filters obtained in the frame of eleven campaigns during variable time sampling durations. However, similar instrumentation, analytical protocol and data processing were performed. Details on field experiments are summarized in Table 2. This chapter presents the different sites with their characteristics, and our attempts for data quality and consistency.

\subsection{European experiments}

In the frame of the European projects CARAMEL and SELF CLEANING GLASS, atmospheric particles were sampled at European urban sites on a weekly basis or twice a month in order to capture their seasonal variations. All sites are primarily impacted by traffic but however might display some differences concerning the relative influence of dieselpowered mobile sources. Some data from the intensive experiment ESCOMPTE are also presented. Site to site variability also originates from meteorological conditions which largely determine possible regional influence and the occurrence of secondary formation for inorganic and organic particles.

\subsubsection{Paris and peri-urban site Gonesse, France}

Two sites were investigated using filter sampling in the French capital city: Downtown, at the top of Saint-Eustache church (40 m); and in a peri-urban environment, at Gonesse, $15 \mathrm{~km}$ away in the northeast, close to the International 
Table 2. Field experiments conducted from 2001 to 2005.

\begin{tabular}{|c|c|c|c|c|c|c|}
\hline \multirow[b]{2}{*}{ Field experiments } & \multirow[b]{2}{*}{ Type } & \multirow[b]{2}{*}{ Date } & \multirow[b]{2}{*}{ Sampling frequency } & \multirow{2}{*}{$\begin{array}{l}\text { number of } \\
\text { samples }\end{array}$} & \multicolumn{2}{|c|}{$\operatorname{Mass}\left(\mu \mathrm{g} / \mathrm{m}^{3}\right)$} \\
\hline & & & & & Fine & Coarse \\
\hline \multicolumn{7}{|l|}{ Europe } \\
\hline PARIS & urban & June 2004-July 2005 & bi-monthly & 28 & 12.3 & 15.8 \\
\hline GONESSE & peri-urban & Sep 2004-July 2005 & weekly & 40 & 13.7 & 9.9 \\
\hline REALTOR & peri-urban & June-July 2001 & day/night & 49 & 13.8 & 10.4 \\
\hline FLORENCE & urban & July 2002-June 2003 & weekly & 52 & 19.2 & 22.8 \\
\hline \multicolumn{7}{|l|}{ China } \\
\hline BEIJING Pek1 & urban & 10-31 Jan 2003 & day/night & 43 & 48.3 & 83.7 \\
\hline Pek1 North & peri-urban & idem & day/night & 47 & 45.6 & 64.2 \\
\hline Pek1 South & peri-urban & idem & day/night & 41 & 31.8 & 71.7 \\
\hline BEIJING Pek2 & urban & 28 Aug-19 Sep 2003 & 4 samples/day & 85 & 55.5 & 75.3 \\
\hline BEIJING Pek3 & urban & 9-27 Aug 2004 & 3 samples/day & 60 & 58.4 & 72.3 \\
\hline Pek3 North & peri-urban & idem & day/night & 36 & 37.4 & 34.0 \\
\hline Pek3 South & peri-urban & idem & daily & 18 & 52.3 & 52.6 \\
\hline
\end{tabular}

Charles-de-Gaulle Airport. Paris Centre (Paris) experiment consisted in bi-monthly samples from June 2004 to July 2005, for both the coarse and the fine aerosol fractions. Gonesse experiment was conducted on a weekly basis from September 2004 to July 2005.

\subsubsection{Florence, Italy}

Florence filter-based experiment was conducted on a weekly basis from July 2000 to June 2003 (Cachier et al., 2004). Figure 1a compares the TEOM PM 10 mass with that obtained by gravimetric measurements. In autumn and winter, the gravimetric mass is systematically higher than the TEOM data. This disagreement appears correlated to nitrate concentrations and atmospheric ambient temperatures (Fig. 1b), pointing out the general risk of volatilisation of a significant fraction of the aerosol in the TEOM sampling procedure. The loss of ammonium nitrate is generally quoted to explain the TEOM missing mass. However, in our data ammonium nitrate represents about $50 \%$ of the missing mass and it may be concluded that other species, most likely semi-volatile organic matter (SVOM), are also lost when heated inlets are used as in the recommended TEOM design. In Florence, this loss is estimated to represent $20 \%$ of the total aerosol mass, and might be sensitive to an air temperature threshold below which TEOM data may be biased. Furthermore in Florence, the TEOM negative artefact during the cold months is likely to be enhanced by the presence of semi-volatile VOC's which accompany emissions from the additional biomass burning source for heating which has been identified to be significant during this period of the year (Cachier et al., 2004). From this experiment, it may be argued that TEOM data are not always adequate for chemical mass closure.
3.1.3 Marseilles and peri-urban site Realtor, South of France

The international project ESCOMPTE (Cros et al., 2004) which took place in the Marseilles region offered the opportunity to investigate the aerosol composition in one of the most polluted regions in France during time periods (JuneJuly 2001, and July 2005) of important photochemical activity. In the present work, Marseilles dataset is used for one DEKATI 13-stage cascade impactor results obtained in July 2005, whereas filter data are from Realtor which is a periurban background site, located $50 \mathrm{~km}$ north of Marseilles city. Filter samples were there collected on a day/night basis from 9 June to 6 July, 2001.

\subsection{Beijing experiments}

Over the years 2003-2004, an intensive filter-based experiment was conducted in Beijing City and its region in the frame of the scientific cooperation between the Beijing $\mathrm{Mu}-$ nicipality and the Ile-de-France Region. The experiment included one-month duration intensive studies in winter 2003 (Pek1) and summers 2003 and 2004 (Pek2 and Pek3) and routine filter samplings in-between (for total mass, carbon and inorganic ions determination). This approach participated to solve a number of key questions on the particle emissions and gas-particle interactions in a complex multisource atmosphere. Three sites were investigated: (1) Downtown, on Chegongzhuang Road, $4 \mathrm{~km}$ West from Tiananmen Square, between the Second and Third Ring Road. Samplings were performed on the roof of Beijing Municipal Environmental Monitoring Centre (BMEMC), about $30 \mathrm{~m}$ above the ground. This site was investigated during Pek1, Pek2 and Pek3 experiments; (2) $40 \mathrm{~km}$ north of Beijing downtown, in a relatively clean background environment, during Pek1 and Pek3; and (3) $50 \mathrm{~km}$ south of Beijing 


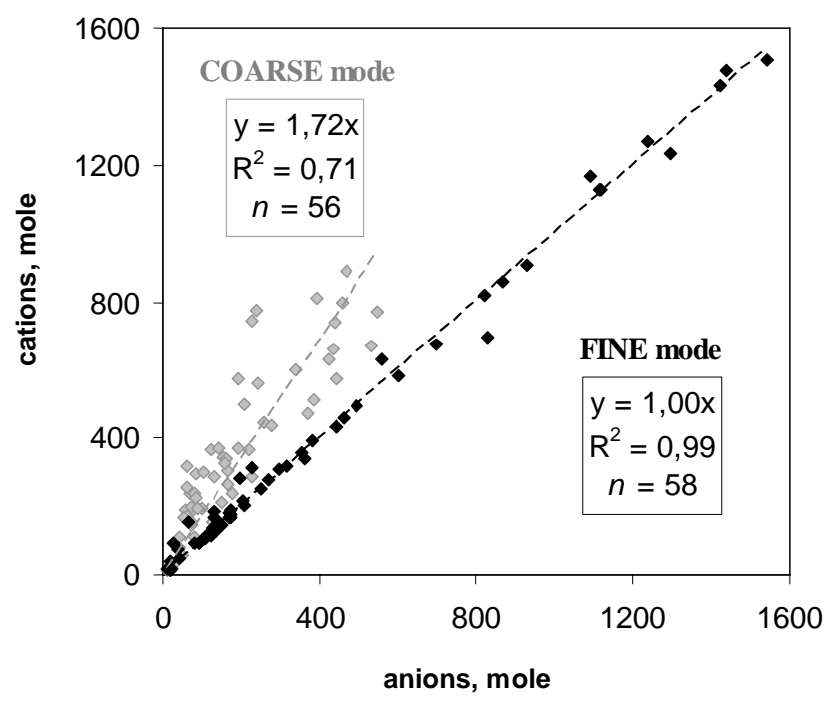

Fig. 2. Ion balance for coarse (in grey) and fine (in black) particles in Pek3 aerosols. Carbonate can be estimated from the excess of cations observed from the coarse mode slope.

downtown, in an environment influenced by local industries and city plumes, during Pek1and Pek3.

At all sites, fine aerosols are found neutral (Fig. 2). Interestingly, in the coarse mode, more than two thirds of $\mathrm{Ca}^{2+}$ (in addition with the other cations) are not balanced by anions which thus indicates that a large fraction of calcium is available for carbonate. Furthermore, it is not excluded that a significant portion of $\mathrm{Ca}^{2+}$ is present as $\mathrm{CaSO}_{4}$ or $\mathrm{Ca}\left(\mathrm{NO}_{3}\right)_{2}$.

\section{Methodology: Reconstructing the mass}

All steps of the methodology are illustrated by the Pek3 experiment results (Fig. 3). The coarse mode and the fine mode mass balances are worked out separately following a 2-step methodology where mass reconstruction relies on two hypotheses applied separately to the main component of the fine and coarse fractions (Fig. 3a):

1. In the coarse mode, the first hypothesis concerns the mass of total dust material, which is estimated from soluble $\mathrm{Ca}^{2+}$ ion concentration using a conversion factor termed $\boldsymbol{f}$;

2. In the fine mode, the critical point is the OC-to-POM conversion factor $\boldsymbol{k}$, which accounts for unmeasured hydrogen, oxygen, and other hetero-atoms in organic materials.

For each mode, the mass closure attempt can be expressed as:

$$
\begin{aligned}
& m_{\text {aerosol weighed }} \geq m_{\text {aerosol retrieved }}= \\
& \Sigma\left[m_{\mathrm{BC}}, m_{\mathrm{POM}}, m_{\text {ions }}, m_{\text {dust }}, m_{n d}\right]
\end{aligned}
$$

where:

$\mathrm{m}_{\mathrm{BC}}$ mass of $\mathrm{BC}$ determined by the reference thermal method;

$\mathrm{m}_{\mathrm{POM}}$ mass of POM estimated from OC obtained from the reference thermal method, using a conversion factor $\boldsymbol{k}$

$\mathrm{m}_{\mathrm{ions}}$ sum of the masses of water-soluble inorganic species determined by IC, except $\mathrm{Ca}^{2+}$ and organic ions (respectively accounted for in dust and POM)

$\mathrm{m}_{\text {dust }}$ Mass of total insoluble and soluble dust material estimated from soluble calcium using the conversion factor $f$ and including calcium carbonate

$\mathrm{m}_{n d}$ not determined mass: difference between $\mathrm{m}_{\text {weighed aerosol }}$ and the sum of $\mathrm{m}_{\mathrm{BC}}, \mathrm{m}_{\mathrm{POM}}, \mathrm{m}_{\mathrm{ions}}$ and $\mathrm{m}_{\text {dust }}$ (see definition $\mathrm{m}_{\text {dust }}$ ).

4.1 Estimating the dust concentration from $\mathrm{Ca}^{2+}$ in the coarse mode

The first step of this method consists in balancing the weighed aerosol mass of the coarse mode with the chemically retrieved mass, which includes ions, BC, and POM. In this first step, we deliberately fixed the OC-to-POM conversion factor $\boldsymbol{k}$ to 1.8 . This relatively high conversion factor may be considered as representative of oxygenated and/or functionalised organic species (Gelencsér, 2004), as one might expect at first approximation for secondary organic material condensed onto coarse particles. In our datasets, as POM generally accounts for 5 to $20 \%$ of the total mass in the coarse mode, sensitivity tests show that conversion factors variability ranging from 1.4 to 2.2 influences the coarse mode chemical mass to $\pm 5 \%$ at most. Any error on this estimation would therefore have little importance for the coarse mode chemical balance.

The difference between the reconstructed coarse mass (sum of BC, POM and ions masses) and the weighed coarse mass provides a substantial missing mass. This missing mass includes species which are not analysed among which the most common are oxides of aluminium, silicon and iron and calcium carbonates $\left(\mathrm{CaCO}_{3}^{-}\right)$. It must be recalled that calcium is assumed to be totally dissolved as $\mathrm{Ca}^{2+}$ during the extraction phase and may be obtained by ion chromatography (see Sect. 2.5).

In all cases, this missing mass is found to be highly correlated to $\mathrm{Ca}^{2+}$ obtained by IC (Fig. 3b).

$\mathrm{Ca}^{2+}=f$. missing mass $+b$

The slope $f$ is related to the abundance of $\mathrm{Ca}^{2+}$ in mineral dust (Eq. 3). As detailed later in the text (Sect. 5) it is shown to be a sensitive indicator of the different dust mixtures.

At all sites, the correlation between $\mathrm{Ca}^{2+}$ and missing mass is sufficiently good $\left(\mathrm{r}^{2}>0.78\right)$ to support the consistency of this simple approach for the evaluation of dust in the coarse fraction of the aerosol. So it may be assessed that the regression coefficient $f$ may be used to calculate mineral dust 

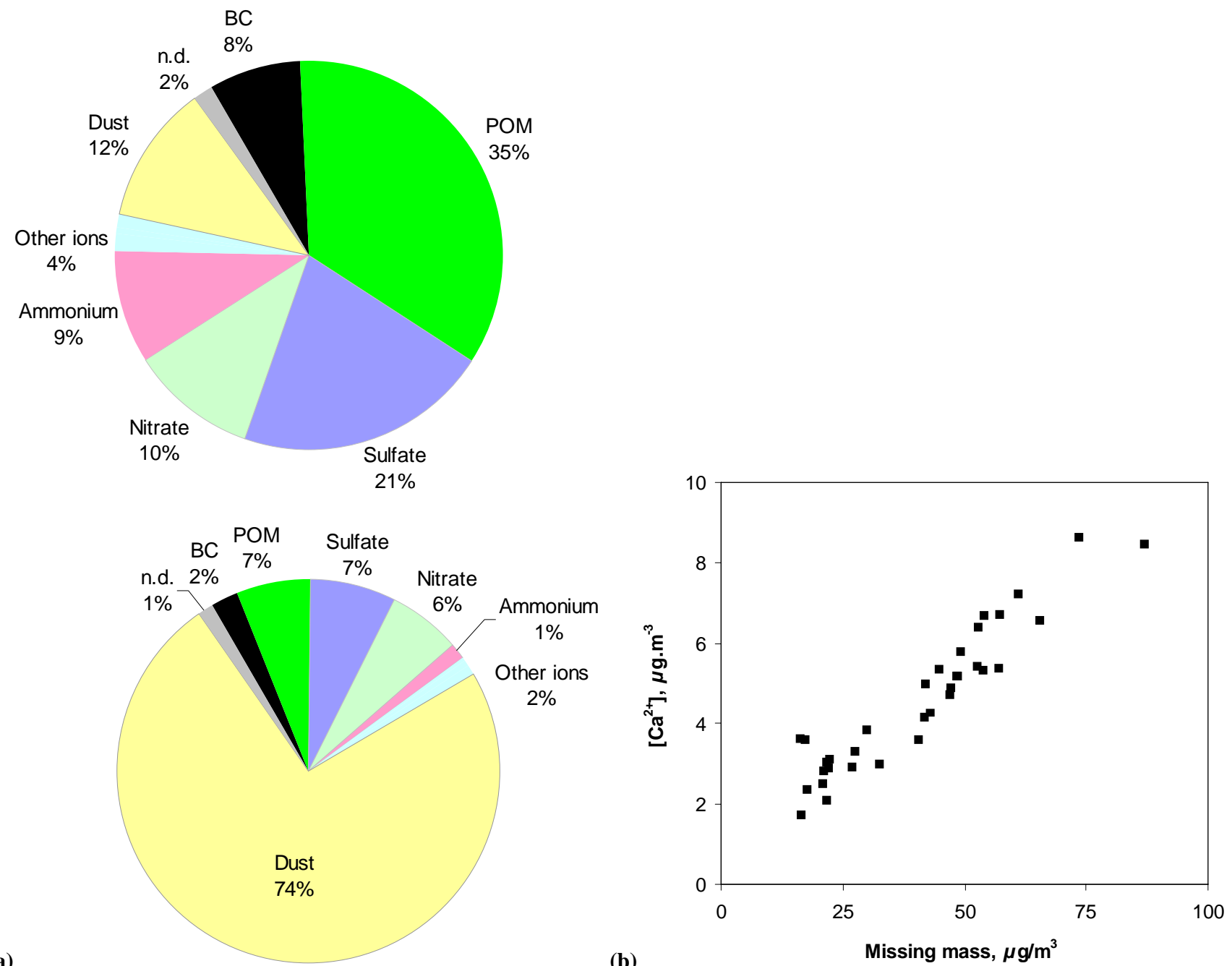

(a)

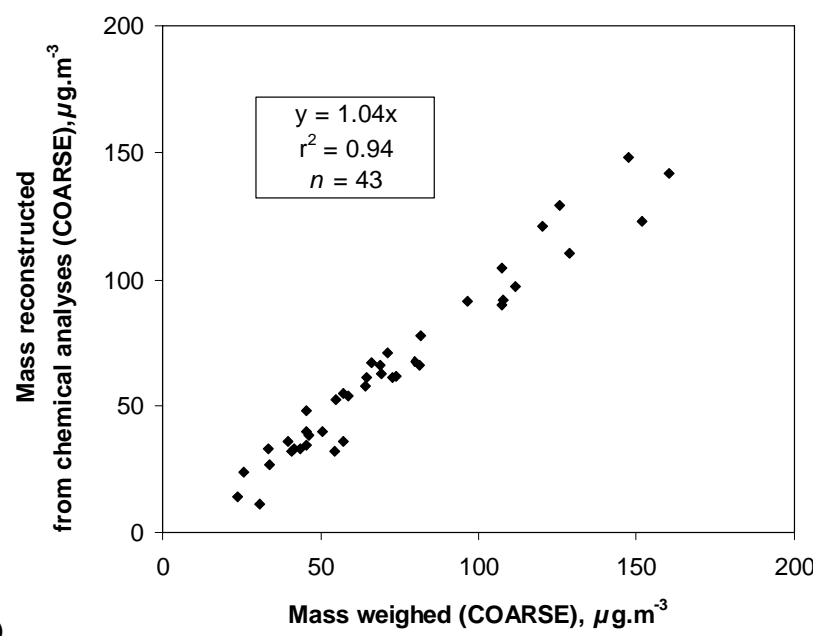

(b)

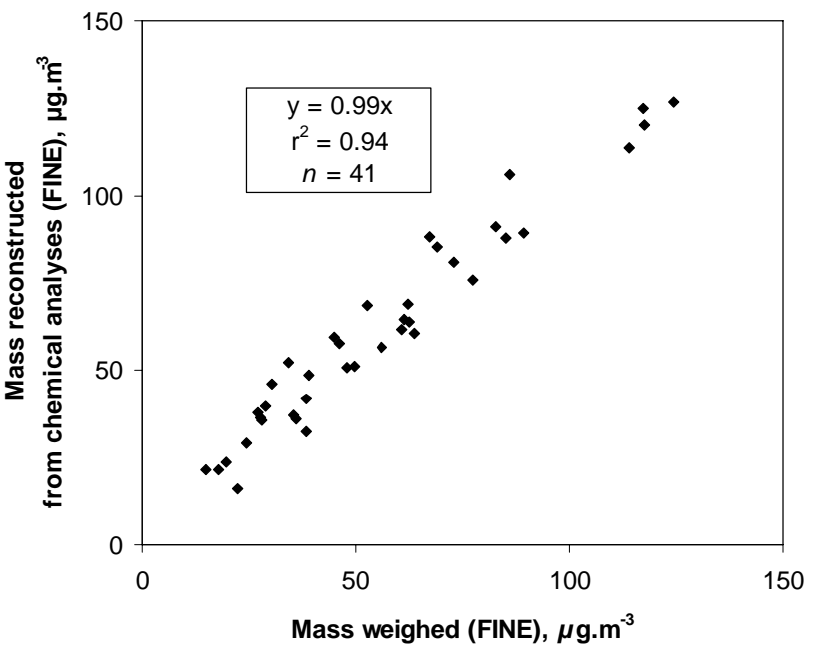

Fig. 3. Mass closure for Pek3 experiment (August 2004), all samples. (a) Mean chemical composition of the coarse (down) and fine (up) modes. (b) Missing mass $/ \mathrm{Ca}^{2+}$ correlation in the coarse mode. (c) Mass closure of the coarse mode: Consistency between the actual weighed mass and the reconstructed mass. (d) Mass closure of the fine mode after $\boldsymbol{k}$ adjustment $(\mathrm{k}=1.65)$. 
amounts (including $\mathrm{CaCO}_{3}^{-}$) from soluble $\mathrm{Ca}^{2+}$ (obtained by IC) following:

mineral dust $=\mathrm{Ca}^{2+} / \boldsymbol{f}$

Using this dust estimate, mass closure of coarse aerosols is achieved with an efficiency ranging between $97 \%$ and $107 \%$ (Fig. 3c).

The intercept $\mathrm{b}$ accounts for $\mathrm{Ca}^{2+}$ which is not associated to insoluble dust, most likely calcium nitrate and sulphate. Conversely, the intercept with the $\mathrm{x}$ axis may account for non-calcium containing dust. These two influences may compete, however at our sites of investigation, $b$ was always found positive or almost null underlining the presence of calcium sulfate and/or nitrate in the coarse mode.

Our work relies on its "self-consistency" and additional value would be given by comparison with more traditional approaches using dust elemental data . Dust composition is variable and site-dependent but a satisfactory approximation of dust mass is classically obtained using multi-element data and the following equation (Pettijohn, 1975):

$$
\begin{aligned}
\text { Dust mass }= & 2.20[\mathrm{Al}]+2.49[\mathrm{Si}]+1.63[\mathrm{Ca}] \\
& +1.42[\mathrm{Fe}]+1.94[\mathrm{Ti}]
\end{aligned}
$$

We could find such data for Beijing aerosols from works of He et al. (2001) and Sun et al. (2004) providing mass, major ions and BC, OC components AND multi- elemental composition for fine and coarse particles. We thus calculated the $\mathrm{Ca} 2+/$ dust $(f)$ ratios for the Beijing experiments illustrated in these other works. There is a notable agreement between all data sets ( $f$ ratio in the narrow range $0.07-0.12$ ). Moreover, Sun et al. (2004) work which provides data for fine and coarse particles confirms our hypothesis of the same composition for fine and coarse dust particles. These results appear to strongly support our simple method as a valuable and robust alternative to dust multi-elemental analysis for aerosol mineral dust content assessments.

\subsection{OC-to-POM conversion factor $\mathrm{k}$ in the fine mode}

Because carbonaceous particles generally account for $50 \%$ to $70 \%$ of the fine aerosol mass, the OC-to-POM conversion factor, $\boldsymbol{k}$, is a crucial parameter in the adjustment of the chemical mass to the gravimetric mass of this fine fraction. $\boldsymbol{k}$ is generally taken in the range 1.2-1.6 for urban aerosols (Putaud et al., 2000; Gelencsér, 2004) with higher values (1.6-2.1) for non urban aerosols (Turpin and Lim, 2001).

Up to now, knowledge on the OC chemical structure remains hardly workable to properly estimate the OC-to-POM conversion factor. Excluding aerosol mass spectrometer (AMS)-based experiments which are able to directly provide POM data, at least three types of approaches are found in the literature:

1. The "best-guess" approach is operational and consists in determining $\boldsymbol{k}$ in order to keep closure exercises as close as possible below 100\% (Hueglin et al., 2005, in Switzerland; He et al., 2001, and Sun et al., 2004, for Beijing particles). Noteworthy, 1.4 is often taken as a common arbitrary conversion factor for urban aerosols (Putaud et al., 2004b).

2. An interesting consideration consists in looking at the nature of the organic matter. WINSOC (Water insoluble organic carbon) are generally fresh primary particles containing organic compounds largely saturated with only few oxygenated functional groups. For WINSOC, a conversion factor of 1.2 may be relevant, following Zappoli et al. (1999). Turpin and Lim (2001) argued for high conversion factors of $1.6 \pm 0.2$ for urban (Los Angeles), and $2.1 \pm 0.2$ for non urban. In the work on Singapore aerosols by Balasubramanian et al. (2003), a different $\boldsymbol{k}$ value is attributed to the two distinct fractions WSOC (Water soluble organic carbon) and WINSOC (Water insoluble organic carbon). Their respective contribution to the OC mass will determine the $\boldsymbol{k}$ value for the total OC fraction. In their work, the adopted WSOC to WSOM conversion factor is 1.8 which is justified by the presence of oxygenated and multifunctional groups. The abundance of WINSOC in the total OC fraction explains the total OC $\boldsymbol{k}$ value of 1.44. As aerosol ageing results in an increase of WSOC abundance, the ageing is also marked by an increase of $\boldsymbol{k}$ value.

3. At last, several studies consider the origin of particles (distinguishing between fresh and aged aerosols) and determine the OC-to-POM conversion factor by analogy with similar environments previously described in the literature (typically "urban" and "non urban"). Following this approach, "consensus" values claimed for aerosols in Europe and in the U.S. has become as high as $1.7 \pm 0.3$ (Putaud et al., 2000; Rees et al., 2004; Kiss et al., 2002).

Some crossing views emerge from the two latter approaches relative to the origin and the age of the particles which are determinant for both the importance WSOC component in the organic aerosols and the $\boldsymbol{k}$ factor value. One may expect $\boldsymbol{k}$ to increase under the influence of aged aerosols at remote locations, or secondary organics at source sites.

The second step of the present method provides $\boldsymbol{k}$ estimates for the aerosol fine mode using the following arguments. Dust is a minor fraction, in the range 0 to $15 \%$ in mass for our dataset. We hypothesize that in both size fractions (fine and coarse modes) dust particles display a similar average composition, which is suggested by previous dust characterizations achieved in Beijing (Cao et al., 2002; Sun et al., 2004). So we calculated dust concentration from fine $\mathrm{Ca}^{2+}$ using the same $f$ coefficient (within the uncertainty range, see Sect. 4.3) determined for the coarse mode. Ions and black carbon masses are obtained straight from analyses of the fine fraction. Finally, $\boldsymbol{k}$ is modulated in order to obtain 
a reconstructed mass as close as possible below the weighed mass (Fig. 3d) and a value of 1.65 is obtained.

\subsection{From sampling to data processing}

This chapter presents the different uncertainties, assumptions and processing features associated to our protocol.

\subsubsection{Uncertainties}

Sampling brings the most important uncertainty because for a given sample, at least three parallel lines are needed. Various inter-comparison of parallel sampling for carbon or ions show that this split into different lines may bring uncertainty up to $10 \%$ of individual concentrations. Uncertainties from analyses are brought by the gravimetric measurements and the carbon measurements as both may influence the aerosol mass from $1 \%$ to $2 \%$. IC analysis uncertainties are found to be one order of magnitude lower. On average, mass concentration uncertainty would reach $4 \%$ affecting the $\boldsymbol{f}$ estimates up to $30 \%$ in the coarse mode (i.e. $\Delta f= \pm 0.02$ ), and the $\boldsymbol{k}$ estimates of $40 \%$ in the fine mode (i.e. $\Delta k= \pm 0.6$ ). Results appear however much more consistent than would suggest this addition of uncertainties for a single sample, which might be due to our procedure relying on an important set of aerosol data for the calculation of the two parameters.As underlined in Sect. 2.4, the BC/OC split may itself be responsible for an important uncertainty on $\boldsymbol{k}$ values which are assessed to be method dependent.

Finally, the small discrepancy remaining between the reconstructed mass and the actual weighed mass may be partly explained by the amount of species not estimated in dust ( $b$ intercept in Eq. 2). This fraction is referred to as $n . d$. (not determined) in our datasets (see Eq. 1).

\subsubsection{Data processing}

Regression data (slopes and intercepts) are obtained from $70 \%$ or more of the available samples, which leads to correlation coefficients $\left(\mathrm{r}^{2}\right)$ mostly better than 0.80 . Mass closure regression slopes are forced to zero. Correlation coefficients $\left(\mathrm{r}^{2}\right)$ are even better if the sampling time period is focussed on a characteristic condition, as achieved during Beijing experiments particularly, distinguishing between up to four different periods per $24 \mathrm{~h}$.

We compared our regression data (slope and intercept) to results estimated from an ordinary least squares regression, and obtained a consistency higher than $95 \%$ for both the fine and coarse modes.

\section{Interpretation and limitation}

\subsection{Dust origin and reactions of neutralization}

In our protocol $\boldsymbol{f}$ might be addressed as a proxy of mineral dust origin and its variations interpreted as source signature. Interactions with other species however may influence this value. Interestingly, in a given region, $f$ exhibits seasonal, temporal and spatial variability. We attempt in this part to assess this approach consistency and its limitations by applying it primarily to our Beijing and Europe data sets. Additional value given by the intercepts is also discussed.

For the Beijing experiment, at each site, $f$ values reflect competing influences between long-range transported dust and more local dust produced by re-suspension. Indeed, each of these two types of dust presents different calcium contents. Long-range transport minerals are likely to be desert dust and to contain important amounts of quartz and feldspar, whereas local dust produced by abrasion processes due to local mechanical stress (wind, traffic, construction) are characterised by calcium-rich minerals like calcite and dolomite (Shi et al., 2003; Kuang et al., 2004). Thus in the Beijing region where dust particles have a mixed origin, an increased influence of desert dust will mark the $f$ coefficient towards smaller values whereas important local dust inputs will shift $f$ towards higher values. Table 3 a shows quite similar $\boldsymbol{f}$ values for Beijing South and Beijing North sites. This feature could point to a regional dust pattern, driven by long-range transport. Both sites display a similar seasonal change (respectively 0.062 and 0.055 in winter, and 0.069 and 0.068 in summer) which could be related to a change of dust source region (Zhang et al., 2003; Washington et al., 2003). Whereas in Beijing Centre, $f$ values are always higher indicating a very active production of local dust probably by traffic and construction works. Dust $f$ values for Beijing Centre are markedly higher in summer (Pek3, $f=0.091$ ), than in winter (Pek1, $f=0.072$ ) which again may be due to the predominance of local dust in summer. In this respect, the remarkably high values obtained for Pek2 (Pek2, $\boldsymbol{f}=0.125$ ), are easily explained by the importance of construction works carried out in the vicinity of the sampling site during the experiment. Additionally, our $\boldsymbol{f}$ results also suggest lower resuspension at night which might be in relation with a decrease of local activities.

$\mathrm{Y}$ axis intercept values confirm the similarity of the periurban Beijing South and Beijing North station dust. Interestingly in Beijing center, a higher sampling frequency allows to point to a significant formation of calcium nitrate and sulfate in the coarse mode during the day especially in the afternoon when photochemical reactions are very active.

The Europe dataset appears consistent too, despite a different sampling procedure regarding frequency (continuous bimonthly sampling) and experiment time-period (12 months). Dust $f$ values are found higher at Paris Centre than at the peri-urban site of Gonesse (0.150 and 0.072 , respectively). 
Table 3a. Results from $\mathrm{Ca}^{2+}$ to the missing mass regressions obtained from the different field campaigns: slope $\boldsymbol{f}$ and intercept b. Coarse mode mass closure efficiency using $\boldsymbol{f}$.

\begin{tabular}{lllllllll}
\hline & $f$ & Intercept b & $r^{2}$ & $n$ & $\%$ Closure & $r^{2}$ & $n$ \\
Europe & & & & & & & \\
PARIS & 0.150 & +0.39 & 0.67 & 20 & 99.7 & 0.78 & 20 \\
GONESSE & 0.072 & +0.19 & 0.90 & 26 & 99.3 & 0.77 & 26 \\
REALTOR & 0.201 & +0.84 & 0.54 & 34 & 97.0 & 0.72 & 40 \\
FLORENCE & 0.120 & +0.33 & 0.56 & 44 & 99.6 & 0.73 & 46 \\
\hline Beijing & & & & & & & \\
WINTER 2003 & & & & & & & \\
Pek1 Day & 0.082 & +0.43 & 0.88 & 15 & 99.8 & 0.95 & 20 \\
Pek1 Night & 0.062 & +0.63 & 0.94 & 14 & 97.9 & 0.96 & 20 \\
Pek1 North & 0.055 & +1.07 & 0.90 & 29 & 97.5 & 0.90 & 29 \\
Pek1 South & 0.062 & +1.07 & 0.78 & 27 & 98.9 & 0.85 & 28 \\
SUMMER 2003 & & & & & & & \\
Pek2 08:00-12:00 h & 0.165 & +0.99 & 0.79 & 15 & 99.6 & 0.66 & 15 \\
Pek2 12:00-16:00 h & 0.159 & +0.99 & 0.91 & 13 & 99.9 & 0.94 & 13 \\
Pek2 16:00-20:00 h & 0.160 & +1.79 & 0.92 & 14 & 99.7 & 0.86 & 14 \\
Pek2 20:00-08:00 h & 0.090 & +0.23 & 0.94 & 16 & 98.8 & 0.64 & 16 \\
SUMMER 2004 & & & & & & & \\
Pek3 07:00-12:00 h & 0.085 & +0.77 & 0.94 & 13 & 106.7 & 0.94 & 14 \\
Pek3 12:00-22:00 h & 0.095 & +0.90 & 0.98 & 12 & 102.5 & 0.93 & 18 \\
Pek3 22:00-07:00 h & 0.099 & +0.42 & 0.92 & 10 & 103.5 & 0.96 & 11 \\
Pek3 North & 0.068 & +0.011 & 0.86 & 27 & 98.9 & 0.93 & 24 \\
Pek3 South & 0.069 & +0.007 & 0.79 & 12 & 99.4 & 0.88 & 12 \\
\hline
\end{tabular}

$\boldsymbol{k}$ coarse are fixed at 1.8

It may be recalled that Paris Centre site is situated at the top of a church where renovation works on calcareous stones are regularly undergone which may influence the dust fraction. Same situation may be quoted for Realtor which is situated close to the calcareous region of Rhone river-delta. $f$ is also influenced by gas-to-particle interactions as $\mathrm{CaCO}_{3}$ is sensitive to acidic species which may create a loss of insoluble material through the formation of condensed calcium salts and subsequent volatilisation of $\mathrm{CO}_{2}$. This capture of gaseous acids by dust is clearly evidenced on cascade impactor data showing associations of $\mathrm{Ca}^{2+}, \mathrm{NO}_{3}^{-}$, and $\mathrm{SO}_{4}^{2-}$ in the coarse mode (Cachier et al., 2005). Therefore, these neutralisation processes are likely to increase the $f$ values and deciphering the respective roles of sources and processes in the $f$ values appears difficult. As sulphate and nitric acid formations are sensitive to photochemistry, they are more abundant in summer than in winter, and during daytime than at night time, which could also explain the temporal trends of sulphate and nitrates (as observed in Table 3a) considering that a significant portion may attach to dust particles. The photochemical formation of secondary sulfate and nitrate and their attachment to the very active calcium-rich dust at Realtor may also explain the high intercept $b$ at this site.

\subsection{OC-to-POM conversion factor $\mathrm{k}$}

In organic aerosols, $\boldsymbol{k}$ reflects the presence of functionalities and is thus very sensitive to the presence of secondary organic particles. Therefore $\boldsymbol{k}$ displays a significant increase with ageing from urban to receptor sites. It is also expected to be higher during time periods when photochemical processes are effective and to display diurnal and seasonal trends at a given site. These general considerations apply in simple situations with a predominant single source, which is the case of urban areas in developed countries where traffic is the overwhelming source.

At our European sites, results obtained are in accordance with these expectations. As shown in Table 3, $\boldsymbol{k} 12$-month averages show an expectable value of 1.4 in Paris and 1.5 in Florence, while the peri-urban sites, Gonesse and Realtor, exhibit a higher $\boldsymbol{k}$ value (1.6). The small difference between the urban Paris and Florence sites might be explained by the influence of 2-strokes engines and biomass burning in the Florence traffic fleet (Cachier et al., 2004).

In Beijing region however, the pattern looks different. $\boldsymbol{k}$ values appear high (1.6-1.7) and do not exhibit conclusive trends. This feature is here attributed to changes in the source mix. Among the four major sources prevailing over the year 
Table 3b. $\boldsymbol{k}$ results estimated from the different field experiments.

\begin{tabular}{lllll}
\hline & $k$ & $\%$ Closure & $r^{2}$ & $n$ \\
Europe & & & & \\
\hline PARIS & 1.40 & 99.1 & 0.89 & 25 \\
GONESSE & 1.60 & 98.7 & 0.86 & 30 \\
REALTOR & 1.60 & 98.2 & 0.85 & 38 \\
FLORENCE & 1.50 & 97.9 & 0.85 & 41 \\
Beijing & & & & \\
WINTER 2003 & & & & \\
Pek1 Day & 1.70 & 99.4 & 0.96 & 20 \\
Pek1 Night & 1.55 & 99.6 & 0.85 & 19 \\
Pek1 North & 1.60 & 99.4 & 0.84 & 29 \\
Pek1 South & 1.85 & 99.2 & 0.90 & 28 \\
SUMMER 2003 & & & & \\
Pek2 08:00-12:00 h & 1.75 & 99.0 & 0.96 & 18 \\
Pek2 12:00-16:00 h & 1.55 & 99.9 & 0.95 & 17 \\
Pek2 16:00-20:00 h & 1.60 & 98.6 & 0.90 & 18 \\
Pek2 20:00-08:00 h & 1.55 & 99.8 & 0.67 & 20 \\
SUMMER 2004 & & & & \\
Pek3 07:00-12:00 h & 1.65 & 99.9 & 0.98 & 14 \\
Pek3 12:00-22:00 h & 1.70 & 99.3 & 0.99 & 17 \\
Pek3 22:00-07:00 h & 1.50 & 99.0 & 0.87 & 12 \\
Pek3 North & 1.55 & 99.8 & 0.92 & 27 \\
Pek3 South & 1.70 & 99.7 & 0.92 & 16 \\
\hline & & & &
\end{tabular}

$f$ fine $=f$ coarse

in Beijing: industries, traffic, coal combustion, and biomass burning, some of them display a pronounced seasonality. In winter, during the heating season, the major source is coal combustion either in industrial settings or for domestic purposes. Coal combustion emissions are expected to contain large amounts of organic aerosols. In winter, coal is certainly the main contributor to the particulate OC fraction of the aerosol and the observed high $\boldsymbol{k}$ values may subsequently characterize the coal combustion source. In summer, coal consumption lowers, and photochemistry and biomass burning (Duan et al., 2004) progressively take over, which maintains high $\boldsymbol{k}$ values. Of interest, while not investigated here, are the effects of meteorological parameters, and precipitations particularly, which are likely to significantly lower $\boldsymbol{k}$ values by subtracting highly functionalized WSOC.

Noteworthy is that the $\boldsymbol{k}$ dataset points to different conditions at night especially during the last experiment (Pek3) where sampling was matching closely the different sources. From other measurements and tracers such as the $\mathrm{BC} / \mathrm{CO}$ (black carbon to carbon monoxide) ratio (Guinot, 2006) it has been hypothesized that a significant additional combustion source was prevailing at night in centre Beijing which is also reflected in the lower calculated $\boldsymbol{k}$ value (1.5). Finally whatever the season, the Beijing South station exhibits remarkably high $\boldsymbol{k}$ values (1.85) whereas the Beijing North
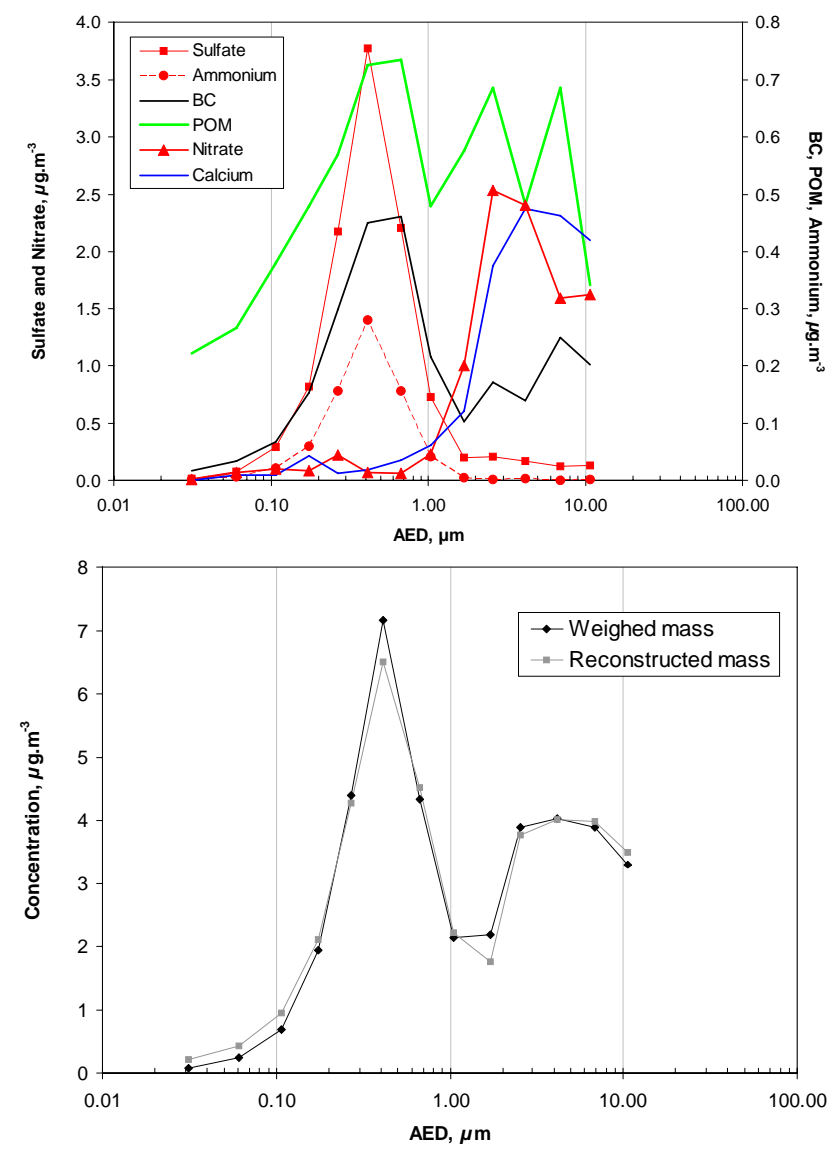

Fig. 4. Size distribution in Marseilles (2 July 2005). (a) Mass size distribution of $\mathrm{BC}, \mathrm{POM}$, sulphate, nitrate, ammonium, calcium. The association between $\mathrm{Ca}^{2+}$ and $\mathrm{NO}_{3}^{-}$is particularly clear in the coarse mode. (b) Consistency between the actual weighed mass and the reconstructed mass over the whole distribution.

station $\boldsymbol{k}$ values remain similar to those obtained in Beijing downtown. This could classify the south site as a "receptor" site with aged aerosols and indicate that general transport is maintained southwards all year long in spite of different local wind conditions (northerlies in winter, breezing southwest to west winds in summer). The influence of an additional local combustion source however may not be excluded, but up to now remains unidentified.

\subsection{Mass closure attempts from cascade impactor data}

We tried to apply the methodology detailed in this paper to the different aerosol mass-size fractions collected on the stages of DEKATI cascade impactors. Tests were performed on four impactors sampled in Beijing, Paris and Marseilles. The complete chemical characterization could be performed for the thirteen stages which theoretically allows to attempt the chemical closure. The mass distribution generally presents two main modes. In Fig. 4 data are detailed for 
Table 4. Concentrations and mass closure achieved on selected stages from DEKATI cascade impactors sampled in Paris, Marseilles, and Beijing (Pek1 and Pek2).

\begin{tabular}{|c|c|c|c|c|c|c|c|c|}
\hline & \multicolumn{2}{|c|}{ Paris } & \multicolumn{2}{|c|}{ Marseilles } & \multicolumn{2}{|c|}{ Beijing Pek1 } & \multicolumn{2}{|c|}{ Beijing Pek2 } \\
\hline Date & $\begin{array}{r}20 \mathrm{Ja} \\
\text { daj }\end{array}$ & $\begin{array}{l}2005 \\
\text { ime }\end{array}$ & $\begin{array}{r}2 \text { Jul } \\
\text { day }\end{array}$ & $\begin{array}{l}2005 \\
\text { me }\end{array}$ & $\begin{array}{r}16 \mathrm{Ja} \\
\text { day }\end{array}$ & $\begin{array}{l}2003 \\
\text { me }\end{array}$ & $\begin{array}{r}11 \mathrm{Se} \\
\text { day }\end{array}$ & $\begin{array}{l}2003 \\
\text { ime }\end{array}$ \\
\hline Dekati stage & 10th & 5 th & 10 th & 4 th & 11 th & 5 th & 10 th & 5 th \\
\hline $\operatorname{AED}(\mu \mathrm{m})$ & 2.580 & 0.267 & 2.604 & 0.176 & 3.189 & 0.330 & 2.580 & 0.267 \\
\hline Weighed mass & 16.13 & 7.81 & 3.89 & 1.94 & 29.10 & 20.69 & 18.19 & 13.51 \\
\hline Reconstructed mass & 15.96 & 7.72 & 3.77 & 1.99 & 29.61 & 20.31 & 18.13 & 13.33 \\
\hline$k$ & 1.80 & 1.40 & 1.80 & 1.40 & 1.80 & 1.70 & 1.80 & 1.70 \\
\hline$f$ & 0.08 & 0.08 & 0.18 & 0.18 & 0.075 & 0.075 & 0.15 & 0.15 \\
\hline $\mathrm{OC}$ & 0.66 & 2.78 & 0.38 & 0.31 & 3.66 & 3.68 & 1.32 & 2.15 \\
\hline $\mathrm{BC}$ & 0.18 & 0.90 & 0.17 & 0.15 & 1.71 & 2.02 & 1.05 & 1.31 \\
\hline POM & 1.19 & 3.89 & 0.69 & 0.44 & 6.60 & 6.25 & 2.38 & 3.66 \\
\hline $\mathrm{SO}_{4}^{2-}$ & 1.29 & 0.76 & 0.18 & 0.81 & 0.96 & 4.54 & 0.55 & 5.50 \\
\hline $\mathrm{NO}_{3}^{-}$ & 1.61 & 0.31 & 0.51 & 0.02 & 0.76 & 2.21 & 1.96 & 0.53 \\
\hline $\mathrm{NH}_{4}^{+}$ & 0.19 & 0.29 & 0.01 & 0.30 & 0.18 & 2.86 & 0.02 & 1.83 \\
\hline $\mathrm{Cl}^{-}$ & 4.34 & 0.08 & 0.02 & 0.01 & 0.28 & 0.56 & 0.08 & 0.04 \\
\hline $\mathrm{Na}^{+}$ & 2.11 & 0.07 & 0.09 & 0.01 & 0.12 & 0.25 & 0.17 & 0.01 \\
\hline $\mathrm{K}^{+}$ & 0.05 & 0.05 & 0.00 & 0.01 & 0.07 & 0.55 & 0.16 & 0.30 \\
\hline $\mathrm{Ca}^{2+}$ & 0.38 & 0.11 & 0.37 & 0.04 & 1.31 & 0.08 & 1.74 & 0.02 \\
\hline Dust & 4.73 & 1.34 & 2.07 & 0.23 & 17.47 & 1.05 & 11.61 & 0.13 \\
\hline Other ions & 0.28 & 0.01 & 0.03 & 0.01 & 0.13 & 0.08 & 0.15 & 0.01 \\
\hline
\end{tabular}

the Marseilles sample and it may be seen that both the reconstructed mass and the actual mass display the same profiles.

It appears from our experience that the distribution modes may overlap so we preferentially worked out the chemical mass closure at stages where a given mode (accumulation or super-micron modes) is overwhelming. The selection of representative stages appeared to be highly critical to properly estimate the conversion factors $\boldsymbol{k}$ and $\boldsymbol{f}$ from the mass closure of a given mode. The accumulation mode is well represented by the 4th or 5th stage (50\% efficiency cut-off: 170 and $270 \mathrm{~nm}$, respectively), and the coarse mode by the 10th or 11th stage (50\% efficiency cut-off: 2.5 and $3.2 \mu \mathrm{m}$ ).

Although calculated here from single samples, $\boldsymbol{k}$ and $\boldsymbol{f}$ coefficient values for the two modes are very similar to those obtained from the corresponding fine/coarse aerosol data set (Table 4). This good agreement suggests that our methodology may consistently apply to aerosols sampled by different protocols.

\section{Conclusion}

This new methodology for aerosol chemical closure gets rid of heavy sampling and analysing means, as it relies on a limited number of allocated sampling lines, and the characterisation of the carbonaceous components and the ion fractions only. As fine and coarse particles are dominated by strikingly different sources, the operational segregation between fine and coarse particles allows to formulate hypotheses sep- arately for these two different modes (with little incidence on the final result) and to retrieve the two parameters which are necessary for the mass closure. In the coarse fraction, which is dominated by dust, the OC-to-POM conversion factor $\boldsymbol{k}$ is fixed arbitrarily supposing OC mainly of secondary origin $(\boldsymbol{k}=1.8)$ and the dust abundance is retrieved by calculating $\boldsymbol{f}$, the $\mathrm{Ca}^{2+} /$ missing mass correlation coefficient. Our results were shown to compare satisfactorily with $\mathrm{Ca}{ }^{2+} /$ dust obtained in the literature from multi-elemental analyses. Conversely, on the fine fraction, as the aim is to obtain the actual conversion factor $\boldsymbol{k}$, the dust conversion parameter $\boldsymbol{f}$ is fixed assuming that dust particles have the same origin as the coarse particles. It must be recalled however that $\boldsymbol{k}$ values may be significantly biased according to the OC/BC separation method, and by the lack of carbonate removal.

In the contrasted environments where we applied this methodology, in Paris and in Beijing regions mainly, correlations leading to the $\boldsymbol{f}$ and $\boldsymbol{k}$ coefficients were found very satisfactory and the aerosol mass closure could be attained for each individual sample whatever the sampling durations and frequencies.

Through the calcium-to-dust relationship ( $\boldsymbol{f}$ coefficient), our methodology provides simple but reliable tools to access to some geochemical perspectives and dust may be clearly distinguished as of local versus long-range transport origin. Although of possible competing influence, evidence is also given for gas- particle interactions in the coarse mode, according to the abundance of secondary acidic species (nitrates, sulphates) in the atmosphere. This dust neutralisation 
calls for a better understanding of the anthropogenic influence on dust particles.

In addition, this methodology allows an original approach and provides useful arguments for the debate on actual $\boldsymbol{k}$ values. As expected $\boldsymbol{k}$ appears to be a relevant proxy for particle origin and ageing and varies in the 1.4-1.8 range in the case of European aerosols dominated by traffic. But in multisources urban situations, $\boldsymbol{k}$ reflects the dominant source and may notably differ to what was previously assumed. This is illustrated by the Beijing case, where fresh aerosols produced by coal combustion could have a $\boldsymbol{k}$ value as high as 1.7. This unexpected value suggests that at this location carbonaceous particles could be still more important than assumed previously (as k adopted values are generally of the order of 1.4) In complex environments such as those encountered in megacities, we may recommend a careful analysis of sources for the choice of an adequate $\boldsymbol{k}$ value.

Acknowledgements. This work relies on data gathered during numerous field experiments. We are indebted to J. Sciare and to other colleagues at LSCE for their participation in the analytical work performed and to BMEMC (Y. Tong and colleagues in Beijing) for help in the experiments.

We gratefully acknowledge support from CEA and CNRS and funding agencies for the following projects:

- The European Commission for CARAMEL (EVK4-CT-200000029) and SELF CLEANING GLASS (NMP3-CT-2003505952)

- French Agencies (CNRS-INSU, ADEME, Ministry of Research) for ESCOMPTE

- The Ile-de-France Region and the Beijing Municipality for the Beijing Aerosol Experiment

- AIRPARIF for experiments at Gonesse

H. Cachier is funded by the University of Paris 7.

Edited by: W. T. Sturges

\section{References}

Andrews, E., Saxena, P., Musarra, S., Hildemann, L. M., Koutrakis, P., McMurry, P. H., Olmez, I., and White, W. H.: Concentration and composition of atmospheric aerosols from the 1995 SEAVS experiment and a review of the closure between chemical and gravimetric measurements, J. Air Waste Manage. Assoc., 50(5), 648-664, 2000.

Balasubramanian, R., Qian, W. B., Decesari, S., Facchini, M. C., and Fuzzi, S.: Comprehensive characterization of PM2.5 aerosols in Singapore, J. Geophys. Res.-Atmos., 108(D16), 4523, doi:10.1029/2002JD002517, 2003.

Berner, A., Galambos, Z., Ctyroky, P., Fruhauf, P., Hitzenberger, R., Gomiscek, B., Hauck, H., Preining, O., and Puxbaum, H.: On the correlation of atmospheric aerosol components of mass size distributions in the larger region of a central European city, Atmos. Environ., 38(24), 3959-3970, 2004.
Birch, M. E. and Cary, R. A.: Elemental carbon-based method for monitoring occupational exposures to particulate diesel exhaust, Aerosol Sci. Technol., 25(3), 221-241, 1996.

Bowen, H. J. M.: Trace Elements in Biogeochemistry, Academic, San Diego, California, 1966.

Cachier, H., Brémond, M. P., and Buat-Ménard, P.: Determination of atmospheric soot carbon with a simple thermal method, Tellus Series B-Chemical and Physical Meteorology, 41(B), 379-390, 1989.

Cachier, H., Sarda, R., Oikonomou, K., Sciare, J., Bonazza, A., Sabbioni, C., Greco, M., Reyes, J., Hermosin, B., and SaizJimenez, C.: Aerosol characterization and sources in different European urban atmospheres: Paris, Seville, Florence and Milan, in: Air Pollution and Cultural Heritage, edited by: Saiz-Jimenez, C., Balkema, 3-14, 2004.

Cachier, H., Aulagnier, F., Sarda, R., Gautier, F., Masclet, P., Besombes, J. L., Marchand, N., Despiau, S., Croci, D., Mallet, M., Laj, P., Marinoni, A., Deveau, P. A., Roger, J. C., Putaud, J. P., Van Dingenen, R., Dell'Acqua, A., Viidanoja, J., Santos, S. M. D., Liousse, C., Cousin, F., Rosset, R., Gardrat, E., and GalyLacaux, C.: Aerosol studies during the ESCOMPTE experiment: an overview, Atmos. Res., 74(1-4), 547-563, 2005.

Cao, L., Tian, W. Z., Ni, B. F., Zhang, Y. M., and Wang, P. S.: Preliminary study of airborne particulate matter in a Beijing sampling station by instrumental neutron activation analysis, Atmos. Environ., 36(12), 1951-1956, 2002.

Chow, J. C., Watson, J. G., Pritchett, L.C., Pierson, W. R., Frazier, C. A., and Purcell, R. G.: The DRI thermal/optical reflectance carbon analysis system: description, evaluation, and applications in U.S. air quality studies, Atmos. Environ., 27(A), 1185-1202, 1993.

Covert, D. S., Kapustin, V. M., Quinn, P. K., and Bates, T. S.: New particle formation in the marine boundary layer, J. Geophys. Res.-Atmos., 97, 20 581-20 589, 1992.

Cros, B., Durand, P., Cachier, H., Drobinski, P., Frejafon, E., Kottmeier, C., Perros, P. E., Peuch, V. H., Ponche, J. L., Robin, D., Said, F., Toupance, G., and Wortham, H.: The ESCOMPTE program: an overview, Atmos. Res., 69(3-4), 241-279, 2004.

Donaldson, K., Stone, V., Clouter, A., Renwick, L., and MacNee, W.: Ultrafine Particles, Occupational and Environmental Medecine, 58, 211-216, 2001.

Duan, F. K., Liu, X. D., Yu, T., and Cachier, H.: Identification and estimate of biomass burning contribution to the urban aerosol organic carbon concentrations in Beijing, Atmos. Environ., 38(9), 1275-1282, 2004.

Gelencsér, A.: Carbonaceous Aerosol, Atmospheric and Oceanographic Sciences Library, 30, Springer (The Netherlands), 350 pp, 2004.

Guinot, B.: Etude physico-chimique de l'aérosol anthropique et de ses évolutions à Pékin, $\mathrm{PhD}$ Thesis (English and French), University Paris 7, 160 pp, 2006.

He, K. B., Yang, F. M., Ma, Y. L., Zhang, Q., Yao, X. H., Chan, C. K., Cadle, S., Chan, T., and Mulawa, P.: The characteristics of PM2.5 in Beijing, China, Atmos. Environ., 35(29), 4959-4970, 2001.

Hoppel, W. A. and Frick, G. M.: Submicron aerosol size distributions measured over the tropical and south Pacific, Atmos. Environ., 24(A), 645-659, 1990.

Hueglin, C., Gehrig, R., Baltensperger, U., Gysel, M., Monn, C., 
and Vonmont, H.: Chemical characterisation of PM2.5, PM10 and coarse particles at urban, near-city and rural sites in Switzerland, Atmos. Environ., 39(4), 637-651, 2005.

John, W., Hering, S., Reischl, G., Sasaki, G., and Goren, S.: Characteristic of Nuclepore filters with large pore size, II, Filtration properties, Atmos. Environ., 17, 373-382, 1983.

Kaufman, Y. J., Tanre, D., and Boucher, O.: A satellite view of aerosols in the climate system, Nature, 419(6903), 215-223, 2002.

Kiss, G., Varga, B., Galambos, I., and Ganszky, I.: Characterization of water-soluble organic matter isolated from atmospheric fine aerosol, J. Geophys. Res.-Atmos., 107(D21), 8339, doi:10.1029/2001JD000603, 2002.

Kuang, C., Neumann, T., Norra, S., and Stuben, D.: Land userelated chemical composition of street sediments in Beijing, Environ. Sci. Pollut., 11(2), 73-83 (PMID 15108854), 2004.

MacMurry, P. H.: A review of atmospheric aerosol measurements, Atmos. Environ., 34(12-14), 1959-1999, 2000.

Malm, W. C., Day, D. E., Carrico, C., Kreidenweis, S. M., Collett, J. L., McMeeking, G., Lee, T., Carrillo, J., and Schichtel, B.: Intercomparison and closure calculations using measurements of aerosol species and optical properties during the Yosemite Aerosol Characterization Study, J. Geophys. Res.Atmos., 110(D14), D14302, doi:10.1029/2004JD005494, 2005.

Penner, J. E., Dong, X. Q., and Chen, Y.: Observational evidence of a change in radiative forcing due to the indirect aerosol effect, Nature, 427(6971), 231-234, 2004.

Pettijohn, F. J.: Sedimentary Rocks, in: Earth data, NY, Harper and Row, 1975.

Putaud, J. P., Van Dingenen, R., Mangoni, M., Virkkula, A., Raes, F., Maring, H., Prospero, J. M., Swietlicki, E., Berg, O. H., Hillamo, R., and Mäkelä, T.: Chemical mass closure and assessment of the origin of the submicron aerosol in the marine boundary layer and the free troposphere at Tenerife during ACE2, Tellus-B, 52, 141-168, 2000.

Putaud, J. P., Van Dingenen, R., Dell'Acqua, A., Raes, F., Matta, E., Decesari, S., Facchini, M. C., and Fuzzi, S.: Size-segregated aerosol mass closure and chemical composition in Monte Cimone (I) during MINATROC, Atmos. Chem. Phys., 4, 889-902, 2004a.

Putaud, J. P., Raes, F., Van Dingenen, R., Bruggemann, E., Facchini, M. C., Decesari, S., Fuzzi, S., Gehrig, R., Huglin, C., Laj, P., Lorbeer, G., Maenhaut, W., Mihalopoulos, N., Mulller, K., Querol, X., Rodriguez, S., Schneider, J., Spindler, G., ten Brink, H., Torseth, K., and Wiedensohler, A.: European aerosol phenomenology-2: chemical characteristics of particulate matter at kerbside, urban, rural and background sites in Europe, Atmos. Environ., 38(16), 2579-2595, 2004b.

Rees, S. L., Robinson, A. L., Khlystov, A., Stanier, C. O., and Pandis, S. N.: Mass balance closure and the federal reference method for $\mathrm{PM}_{2.5}$ in Pittsburgh, Pennsylvania, Atmos. Environ., 38(20), 3305-3318, 2004.
Schmid, H., Laskus, L., Abraham, H. J., Baltensperger, U., Lavanchy, V., Bizjak, M., Burba, P., Cachier, H., Crow, D., Chow, J., Gnauk, T., Even, A., ten Brink, H. M., Giesen, K. P., Hitzenberger, R., Hueglin, E., Maenhaut, W., Pio, C., Carvalho, A., Putaud, J. P., Toom-Sauntry, D., and Puxbaum, H.: Results of the "carbon conference" international aerosol carbon round robin test stage I, Atmos. Environ., 35(12), 2111-2121, 2001.

Sciare, J., Oikonomou, K., Cachier, H., Mihalopoulos, N., Andreae, M. O., Maenhaut, W., and Sarda-Esteve, R.: Aerosol mass closure and reconstruction of the light scattering coefficient over the Eastern Mediterranean Sea during the MINOS campaign, Atmos. Chem. Phys., 5, 2253-2265, 2005, http://www.atmos-chem-phys.net/5/2253/2005/.

Seinfeld, J. H. and Pandis, S. N.: Atmospheric Chemistry and Physics, J. Wiley and Sons (Inc), New York, 1998.

Shi, Z. B., Shao, L. Y., Jones, T. P., Whittaker, A. G., Lu, S. L., Berube, K. A., He, T., and Richards, R. J.: Characterization of airborne individual particles collected in an urban area, a satellite city and a clean air area in Beijing, 2001, Atmos. Environ., 37(29), 4097-4108, 2003.

Sun, Y. L., Zhuang, G. S., Ying, W., Han, L. H., Guo, J. H., Mo, D., Zhang, W. J., Wang, Z. F., and Hao, Z. P.: The air-borne particulate pollution in Beijing - concentration, composition, distribution and sources, Atmos. Environ., 38(35), 5991-6004, 2004.

Ten Brink, H., Maenhaut, W., Hitzenberger, R., Gnauk, T., Spindler, G., Even, A., Chi, X. G., Bauer, H., Puxbaum, H., Putaud, J. P., Tursic, J., and Berner, A.: INTERCOMP2000: the comparability of methods in use in Europe for measuring the carbon content of aerosol, Atmos. Environ., 38(38), 6507-6519, 2004.

Turpin, B. J. and Lim, H. J.: Species contributions to PM2.5 mass concentrations: Revisiting common assumptions for estimating organic mass, Aerosol Sci. Technol., 35(1), 602-610, 2001.

Washington, R., Todd, M., Middleton, N. J., and Goudie, A. S.: Dust-storm source areas determined by the total ozone monitoring spectrometer and surface observations, Annals of the Association of American Geographers, 93(2), 297-313, 2003.

Whitby, K. T.: The physical characteristics of sulfur aerosols, Atmos. Environ., 12, 135-159, 1978.

Zappoli, S., Andracchio, A., Fuzzi, S., Facchini, M. C., Gelencser, A., Kiss, G., Krivacsy, Z., Molnar, A., Meszaros, E., Hansson, H. C., Rosman, K., and Zebuhr, Y.: Inorganic, organic and macromolecular components of fine aerosol in different areas of Europe in relation to their water solubility, Atmos. Environ., 33(17), 2733-2743, 1999.

Zhang, X. Y., Gong, S. L., Shen, Z. X., Mei, F. M., Xi, X. X., Liu, L. C., Zhou, Z. J., Wang, D., Wang, Y. Q., and Cheng, Y.: Characterization of soil dust aerosol in China and its transport and distribution during 2001 ACE-Asia: 1. Network observations, J. Geophys. Res.-Atmos., 108(D9), 4261, doi:10.1029/2002JD002632, 2003. 